\title{
Experimental and Numerical Studies on the Inflatable Recyclable Anchor in the Tube Piece Type Based on the Soil-Anchor Interaction Mechanism
}

\author{
Chenchen Du $\mathbb{D}$, ${ }^{1}$ Taoli Xiao $\mathbb{D}^{1,2}$, Yunlong He $\mathbb{D}^{1},{ }^{1}$ and Xuexiang Yang $\mathbb{D}^{1}$ \\ ${ }^{1}$ School of Urban Construction, Yangtze University, Jingzhou 434000, China \\ ${ }^{2}$ State Key Laboratory of Geomechanics and Geotechnical Engineering, Institute of Rock and Soil Mechanics, \\ Chinese Academy of Sciences, Wuhan 430071, China
}

Correspondence should be addressed to Taoli Xiao; 200536@yangtzeu.edu.cn

Received 20 July 2020; Revised 27 May 2021; Accepted 14 August 2021; Published 24 August 2021

Academic Editor: Daniele Baraldi

Copyright (C) 2021 Chenchen Du et al. This is an open access article distributed under the Creative Commons Attribution License, which permits unrestricted use, distribution, and reproduction in any medium, provided the original work is properly cited.

This paper deeply studies the characteristics and "uplift bearing capacity" of a novel type of inflatable recyclable anchor in the tube piece. The proposed novel inflatable recyclable anchor in the tube piece type comprises a metallic rod, an inflatable anchorage device, and a recovery device. Fifteen field uplift tests are conducted to investigate the effects of inflation pressure, thickness of the steel disc, embedment length, and time lapse between anchor inflation and pullout on "the uplift bearing capacity." The results show that "the uplift bearing capacity" of the novel inflatable anchor in the tube piece type increases with the increase of inflation pressure, thickness of the steel disc, and embedment length. With the increase of inflation time, "the uplift bearing capacity" of the novel inflatable anchor experiences an increase after first experiencing a decrease. The finite element analysis method is used to establish a numerical analysis model of the inflatable anchor, and the distribution law of the tensile stress of the surrounding soil during the pullout of the anchor is analysed. Compared with the traditional grouted anchor, the proposed anchor has an obvious superiority in recyclability, reusability, and swifter formation of anchorage force and thus is a resource-saving and environmentally friendly anchor technology.

\section{Introduction}

Anchor bolt technology has a wide range of applications in engineering practice [1-5]. The inflatable anchor is a type of head-expansion anchor, which can provide "uplift bearing capacity" by using the dilated anchor solid to squeeze the surrounding soil. Airbag is arranged in the anchoring section of the inflatable anchor. Airbag is inflated to squeeze the soil to achieve anchoring effect when anchoring is needed. The airbag is emptied at the end of anchoring, and the anchor rod body, together with the airbag, can be pulled out of the anchor hole as a whole, without leaving any component in the soil, so as to realize the complete recovery of the anchor bolt. Originated from oceanographic engineering, this kind of anchor is used to provide an antifloating anchorage force for equipment or machines at the bottom of the sea. In 2000, Newson et al. [6] conducted the laboratory experiment on the inflatable anchor and found that "the ultimate uplift bearing capacity" of the inflatable anchor can be four times of the traditional screw anchor under the same testing conditions. In 2003, Newson et al. [7] conducted further uplift tests in which inflatable anchors were embedded in drain and undrained conditions to emulate the typical grading and characteristics of a North Sea deposit in Canada. It was found that "the ultimate uplift bearing capacity" of the inflatable bolt was $0.34 \mathrm{kN}$ with a shift of $75 \mathrm{~mm}$, an anchor length of $100 \mathrm{~mm}$, an embedment depth of $140 \mathrm{~mm}$, and an inflation pressure of $150 \mathrm{kPa}$ for 16 hours. Then, Newson et al. [8] and Liang et al. [9] verified that there is an obvious dependent relation between "the ultimate uplift bearing capacity" of the inflatable bolt and the strength characteristics of soft clay, dissipation time of pore water 
pressure, among others. "The ultimate uplift bearing capacity" of the inflatable bolt, as determined through a Plaxis simulation, was $0.31 \mathrm{kN}$. In 2009, Liang et al. [10] and Newson et al. [11] conducted scaled physical model tests and Plaxis numerical simulations to investigate the factors that influence "the uplift bearing capacity" of inflatable anchors embedded in Congleton silica sand. Factors such as anchor length, inflation pressure, density of sand, and surface roughness of the membrane were taken into consideration, and "the ultimate uplift bearing capacity" of the inflatable anchor in sandy soil was estimated to be $0.31 \mathrm{kN}$ with a displacement of $36 \mathrm{~mm}$ (anchor length, $L=300 \mathrm{~mm}$; inflation pressure, $P=150 \mathrm{kPa}$; embedment cover, $H=140 \mathrm{~mm}$; rubber thickness, $t=3.13 \mathrm{~mm}$; and soil density, $\left.\rho=1.56 \mathrm{t} / \mathrm{m}^{3}\right)$. In 2011, Cao et al. $[12,13]$ conducted laboratory experiments on an optimally designed Tim Newson inflatable anchor (an anchor length of $200 \mathrm{~mm}$, an inflation pressure of $100 \mathrm{kPa}$, an embedment cover of $400 \mathrm{~mm}$, and a rubber thickness of $2 \mathrm{~mm}$ ). The researchers discovered that the ultimate uplift bearing capacities of the inflatable anchor in sandy soils with sand densities of $1.54 \mathrm{t} / \mathrm{m}^{3}$ and $1.67 \mathrm{t} / \mathrm{m}^{3}$ are $0.303 \mathrm{kN}$ with a shift of $34.05 \mathrm{~mm}$ and $0.639 \mathrm{kN}$ with a shift of $40.0 \mathrm{~mm}$, respectively.

There are many different methods for investigating material performance. Methods include the use of sensors to detect damage and monitor structural health (i.e., structural health monitoring) [14-18], numerical simulations [19-24], and experiments combined with numerical simulations [25-31]. For the study of the mechanical properties of the inflatable anchor in this paper, the field test method was mainly used. In 2020, in an effort to figure out the consequence of anchor bolts on the supporting effect of the layered weak roof and the surrounding rock of the nonlayered roof with good integrity, Chao et al. [32] analysed the distribution characteristics of the stress field and displacement field of bolt support by using FLAC3D numerical simulation software. In addition, the application of finite element analysis has become a better research method in the study of different soil types, anchor spacing, and load size [33]. The above research shows that the use of finite element analysis has certain feasibility and scientificity in the research of bolt anchoring effect.

The inflatable anchor has an obvious superiority in recyclability, reusability, and swifter formation of anchorage force and thus is a resource-saving and environmentally friendly anchor technology, suitable for a wide range of applications. However, the development of inflatable anchors is still in the stage of model test. The drawing bearing force is low compared to the grouted anchor and still cannot meet the typical requirements of practical engineering. Prior research $[10,12,13]$ observed that the major factors determining the ultimate drawing bearing force of an inflatable anchor bolt are the inflation pressure and the size of the rubber pneumatic bag. In other words, "the uplift bearing capacity" is highly dependent on the friction force generated between the dilated rubber pneumatic bag and the rock mass. In practice, the condition of the rock mass is certain and unchangeable. Thus, to improve the drawing bearing force, the structure of the inflatable anchor bolt needs optimization.
In the previous research done by Xiao and He [34], the factors affecting "the uplift bearing capacity" of the inflatable anchor were concentrated on inflation pressure, embedment depth, and length of the rubber pneumatic bag, which were not comprehensive enough. For example, inflation time has a great influence on the formation of anchorage force and "uplift bearing capacity of the inflatable anchor," but this factor has not been examined in depth. In this study, the factors of inflation pressure, thickness of the steel disc, embedment depth (including the relative embedment depth), time lapse between anchor inflation and pullout, and the steel disc surface roughness are investigated by operating fifteen field tests. The potential for practical applications is also discussed by means of comparing with previously studied inflatable anchors and traditional grouted anchors. On this basis, the stress field distribution law of the surrounding soil under the pullout of the novel anchor is analysed by using ABAQUS numerical simulation software. And the anchoring mechanism of the anchor is discussed in detail.

\section{Experimental Studies}

2.1. Materials and Attributes. The tests were operated in the vacant ground located in Yangtze University. The soil layer is distributed as follows: the surface of the ground is covered with $0.8 \mathrm{~m}$ plain fill, and the underside is filled with $2.4 \mathrm{~m}$ silt clay. Before the tests, the SL 237-1999 code [35] was used as a guide to measure the physical and mechanical attributes of the proposed soil layers. The filling soil, which has a unit weight $\gamma_{1}=18.0 \mathrm{kN} / \mathrm{m}^{3}$, did not have stable mechanical properties. The silt clay properties were obtained through a direct shear test. The silty clay soil has a unit weight $\gamma_{2}=19.1 \mathrm{kN} / \mathrm{m}^{3}$, the rate of the natural moisture content is $\omega=30.9 \%, \quad \omega_{L}=36.7 \%$, and $\omega_{P}=23.2 \%$, the cohesive strength is $20.5 \mathrm{kPa}$, and the angle of internal friction is about $9^{\circ}$. In the above parameters, $\omega_{L}$ is defined as limited water of soil from the plastic state to the flowing state, and $\omega_{P}$ is defined as limited water of soil from the plastic state to the semisolid state.

According to Liang et al. [10], the ultimate uplift bearing capacities of the inflatable anchor bolt are closely related to the embedment depth and the length of the airbag, and the effect of limit embedment depth should be taken into consideration. Furthermore, the plain filling soil on the surface of the site has a loose structure, high compressibility, and unstable mechanical properties and is thus not suitable to function as the anchorage soil for the inflatable anchor. Therefore, the anchorage end of the inflatable anchor needs to be located in the deeper silt clay layer when conducting the experiment. The length of the anchorage end is $250 \mathrm{~mm}$, and the embedment depth is no less than $1.5 \mathrm{~m}$. The inflation pressure was generated by a computer-controlled pressurization system, and loads were generated by a hollow jack. "The uplift bearing capacity" was monitored using a special anchor instrument (ZY-2), and the anchor displacement was monitored with a dial gauge which is supported on the reaction frame. The reaction frame of two 12\# beam channels was welded together. In order to minimize the 
possible effect of compression of the soil layer on the displacement measurements, two precast concrete piles served as the base of the reaction frame. A schematic of the novel inflatable anchor and photo of the experiment are shown in Figure 1.

2.2. The New Inflatable Anchor. As shown in Figure 1, the inflatable anchor system consists of a metal rod, an inflatable anchorage device, and a recovery device. The inflation anchorage device consists of a rubber pneumatic bag and an array of steel discs and panels, as shown in Figure 2(a). The lateral steel panels (Figure 2(b)) are hinged with the circular steel disc (Figure 2(c)) and can rotate around the circular steel disc. The panels are constructed by hinging trapezoidal and rectangular segments together. Each trapezoidal segment has a length of $50 \mathrm{~mm}$, and each rectangular segment has a length of either $100 \mathrm{~mm}$ or $200 \mathrm{~mm}$. The designed lengths of the segments allow the steel panels to always be able to wrap around the inflatable pneumatic bag when the rubber bag is dilated. In order to ensure the tightness of the airbag, highquality butyl rubber is chosen to manufacture the rubber pneumatic bag, whose diameter is $100 \mathrm{~mm}$, hollow inner diameter is $30 \mathrm{~mm}$, length is $250 \mathrm{~mm}$, and thickness is $2 \mathrm{~mm}$. The specific size and structure of the rubber pneumatic bag are shown in Figure 2(d). The hollow structure of the pneumatic bag allows easy connection with the metal rod. The steel panels limit the vertical expansion of the bag so that only radial expansion occurs during inflation of the bag, which forms an ideal drum shape. The lateral steel panels increase the contact area between the anchor and the surrounding soil wall, which consequently enhances the anchoring force. Metal rods with a diameter of $18 \mathrm{~mm}$ collectively served as a tension bar and are connected with each other by screw sockets after truncated as sections with a length of $1 \mathrm{~m}$. The recovery device consists of steel wires and a fixed line socket, and the anchorage fixture is mainly composed of a reaction frame built by two welded 12\# beam channels and nuts. For the inflatable anchor of this structure, although the bearing capacity is improved compared with the traditional anchor, there are many problems: (1) the rubber bladder is prone to blasting, which causes damage to the anchor structure and cannot continue to provide anchoring force. (2) The bearing capacity of the inflatable anchor is not high, and the deformation is large. (3) The inflation pressure value is unstable. Based on the above problems, the research team optimized the design of the structure of the inflatable anchor through market research analysis, theory, and model test research. After going through several different stages such as the structural form with the end baffle, the structural form with side guards, and the application of the computer control system for inflation pressure, a relatively mature inflatable anchor structure system has been formed at this stage.

\section{Experimental Results}

Prior research $[11,36,37]$ has found that one of the main factors affecting "the uplift bearing capacity" of the inflatable anchor is the interface between the anchor and rock matrix.
In this study, based on the mechanical characteristics of the new anchor and the past research, in order to explore the consequences of inflation pressure, steel thickness, embedment depth, and time lapse between anchor inflation and pullout on "the uplift bearing capacity" of the proposed inflatable anchor, fifteen field uplift tests were conducted. The test results are listed in Table 1.

3.1. Effect of Inflation Pressure $(P)$. Figure 3 indicates the influence of inflation pressure on "the uplift bearing capacity" of the new anchor. For this group of tests, the embedment depth $(H)$ was held constant at $1500 \mathrm{~mm}$, the steel disc thickness $(t)$ was $2 \mathrm{~mm}$, the time lapse between anchor inflation and uplift $(T)$ was $30 \mathrm{~min}$, and the inflation pressure $(P)$ was increased from $100 \mathrm{kPa}$ to $400 \mathrm{kPa}$. The data shown in Figure 3 suggest that increasing inflation pressure leads to an increase in "uplift bearing capacity" of the proposed inflatable and recyclable anchor. When the inflation pressures are $100 \mathrm{kPa}, 200 \mathrm{kPa}, 300 \mathrm{kPa}$, and $400 \mathrm{kPa}$, "the ultimate uplift bearing capacity" of the novel inflatable and recyclable anchor is $4.12 \mathrm{kN}, 6.01 \mathrm{kN}, 8.42 \mathrm{kN}$, and $11.42 \mathrm{kN}$. From another point of view, "the ultimate uplift bearing capacity" is increased to 1.46 times, 1.40 times, and 1.36 times of the previous inflation pressure value, respectively. Furthermore, "the uplift bearing capacity" is directly plotted against inflation pressure which is analysed in Figure 4 to show that "the ultimate peak uplift bearing capacity" of the anchor showed an exponential trend of increase with inflation pressure. The main reason can be explained as follows: with the increase of inflation pressure, the steel sheet and soil contact more closely, so the lateral resistance between the soil and anchor increases. On the contrary, it is found that increasing inflation pressure leads to "the residual uplift bearing capacity" increasing linearly.

According to Figure 3, it is found that the load-displacement curve variance goes through three stages: elastic stage, plastic stage, and ductile stage. In the elastic stage, the load shows near linear growth with displacement. In view of this situation, one parameter $(K)$ can be defined in the elastic stage, $K=L / D$, where $L$ is the load $(\mathrm{kN})$ and $D$ is the corresponding displacement $(\mathrm{mm})$. The $K$ value, which can be explained as the load required to produce unit displacement of the anchor, reflects the ability of the anchor to resist deformation, and the greater the $K$ value is, the stronger the ability of the anchor to resist deformation will be. When the inflation pressure is $100 \mathrm{kPa}, 200 \mathrm{kPa}, 300 \mathrm{kPa}$, and $400 \mathrm{kPa}$, the $K$ values are $0.68 \mathrm{kN} / \mathrm{mm}, 0.86 \mathrm{kN} / \mathrm{mm}, 0.80 \mathrm{kN} / \mathrm{mm}$, and $0.86 \mathrm{kN} / \mathrm{mm}$, respectively. On the contrary, it can be found from Figure 3 that the variation tendency of four loaddisplacement curves is similar under different inflation pressures. When the load reaches its maximum (peak uplift force), "the uplift bearing capacity" abruptly decreases, and then "the uplift bearing capacity" drops to a fixed value (residual uplift force) gradually. With the variance of the inflation pressure, the difference value between peak pullout force and residual pullout force, which is defined as $\Delta_{F}$, is changed correspondingly. When the inflation pressure is $100 \mathrm{kPa}, 200 \mathrm{kPa}, 300 \mathrm{kPa}$, and $400 \mathrm{kPa}, \Delta_{F}$ is decreased to 


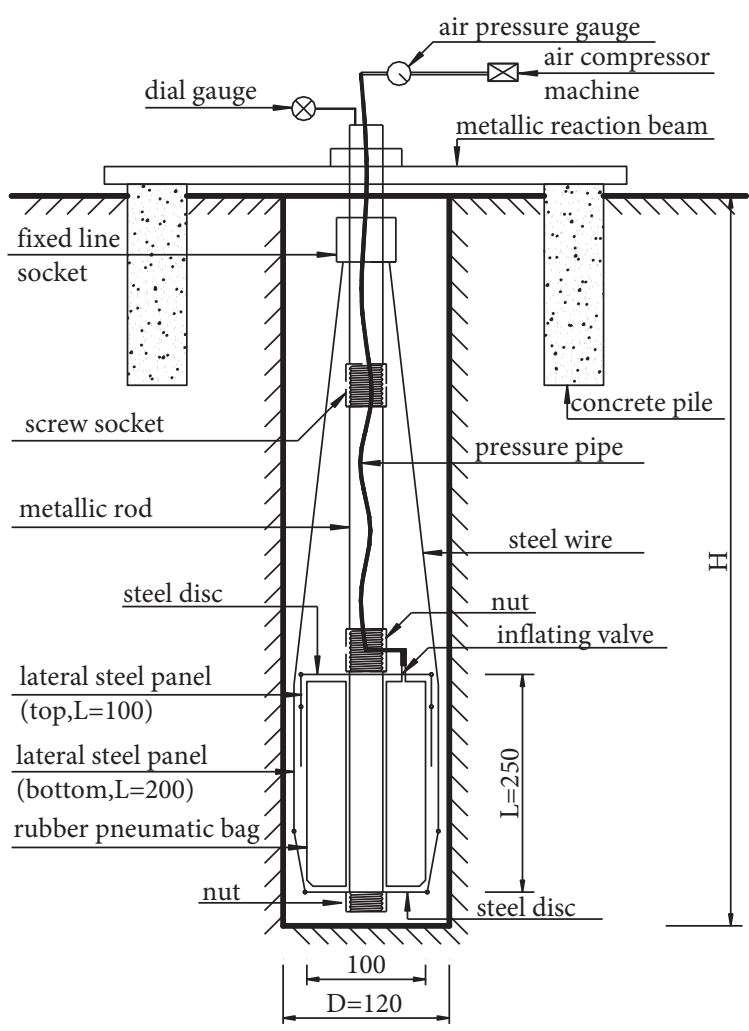

(a)

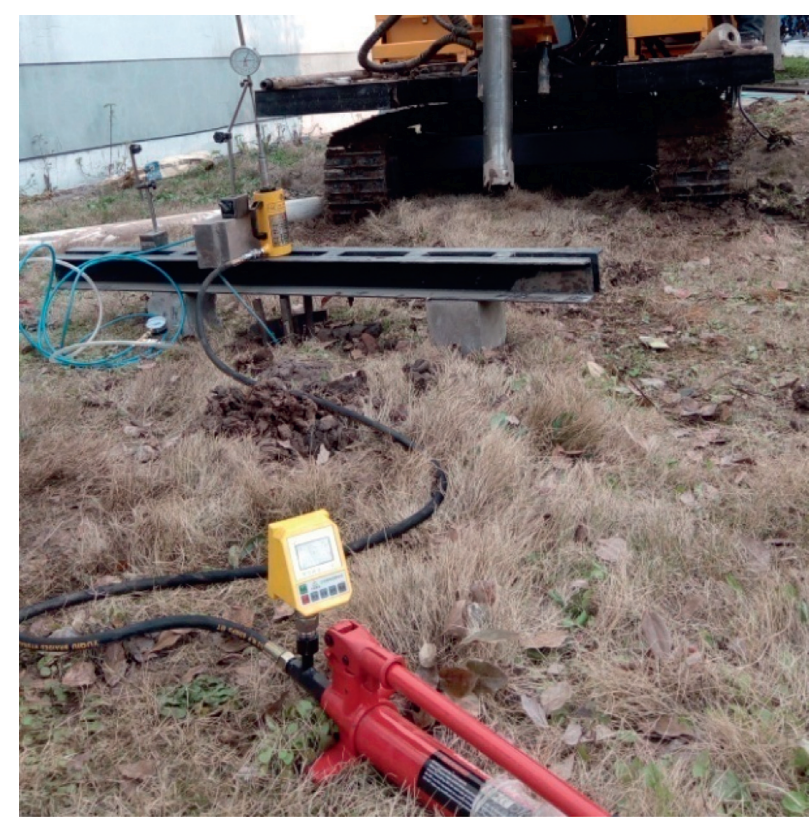

(b)

FIGURE 1: Schematic of the experimental setup. (a) Equipment schematic (unit: mm). (b) Photo of the experiment on the ground level [34].

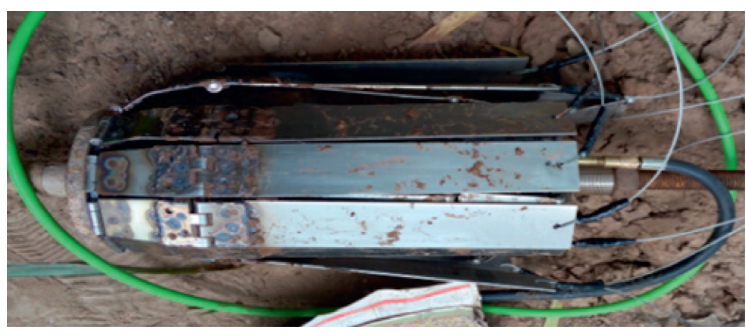

(a)

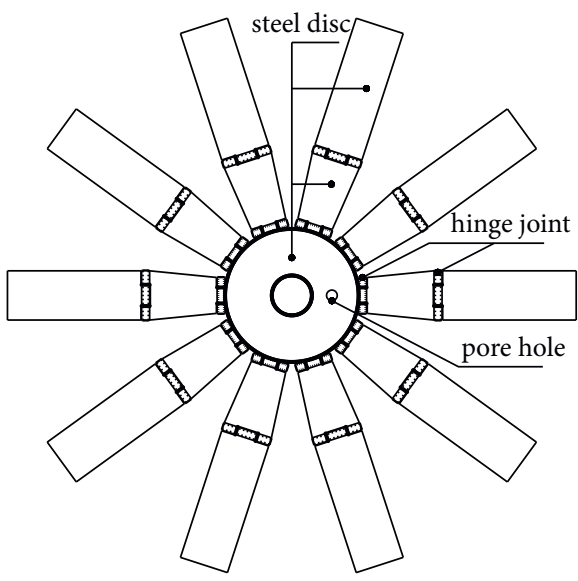

(c)

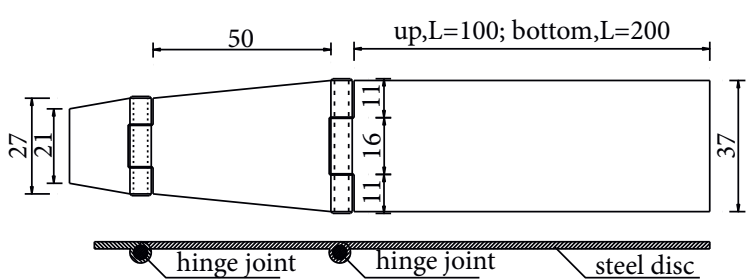

(b)

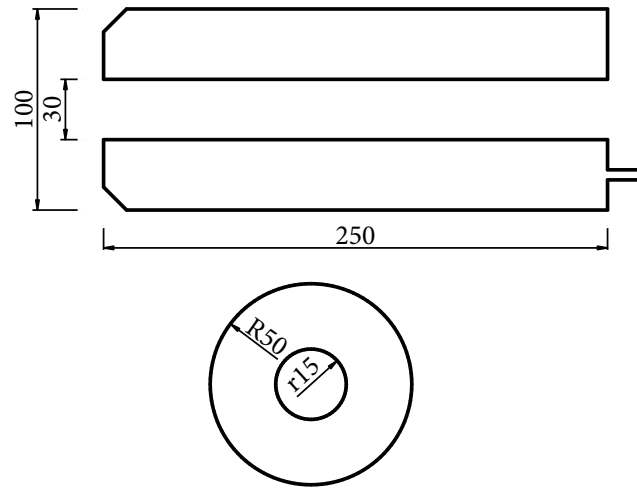

(d)

Figure 2: The new inflatable anchor details. (a) Inflatable anchor. (b) Lateral steel panel (unit: mm). (c) Top and bottom steel discs (unit: $\mathrm{mm}$ ). (d) Rubber pneumatic bag (unit: $\mathrm{mm}$ ). 
TABLE 1: Summary of the field experiments.

\begin{tabular}{|c|c|c|c|c|c|c|c|}
\hline Test no. & $\begin{array}{c}\text { Inflation } \\
\text { pressure } P \\
(\mathrm{kPa})\end{array}$ & $\begin{array}{c}\text { Embedment } \\
\text { depth } H(\mathrm{~mm})\end{array}$ & $\begin{array}{c}\text { Steel disc } \\
\text { thickness } t \\
(\mathrm{~mm})\end{array}$ & $\begin{array}{c}\text { Time lapse between } \\
\text { anchor inflation and } \\
\text { uplift } T(\mathrm{~min})\end{array}$ & $\begin{array}{c}\text { Peak uplift } \\
\text { force } P_{\text {ult }} \\
(\mathrm{kN}) \\
\end{array}$ & $\begin{array}{l}\text { The corresponding } \\
\text { displacement at } P_{\text {ult }} \mathrm{s} \\
(\mathrm{mm})\end{array}$ & $\begin{array}{c}\text { Residual } \\
\text { uplift force } R \\
(\mathrm{kN})\end{array}$ \\
\hline 1 & 100 & 1500 & 2 & 5 & 4.12 & 6.02 & 3.55 \\
\hline 2 & 200 & 1500 & 2 & 5 & 6.01 & 6.96 & 5.55 \\
\hline 3 & 300 & 1500 & 2 & 5 & 8.42 & 10.53 & 7.26 \\
\hline 4 & 400 & 1500 & 2 & 5 & 11.42 & 13.23 & 9.98 \\
\hline 5 & 200 & 1500 & 1 & 5 & 5.17 & 8.96 & 4.45 \\
\hline 6 & 200 & 1500 & 5 & 5 & 6.52 & 11.51 & 5.67 \\
\hline 7 & 200 & 1500 & $5^{*}$ & 5 & 6.94 & 9.32 & 5.85 \\
\hline 8 & 300 & 1500 & 1 & 5 & 6.92 & 10.68 & 5.94 \\
\hline 9 & 300 & 1500 & 5 & 5 & 8.64 & 14.44 & 7.39 \\
\hline 10 & 300 & 1500 & $5^{*}$ & 5 & 9.22 & 12.87 & 7.84 \\
\hline 11 & 300 & 2000 & 2 & 5 & 9.29 & 10.78 & 8.15 \\
\hline 12 & 300 & 2500 & 2 & 5 & 10.54 & 11.06 & 9.06 \\
\hline 13 & 300 & 1500 & 2 & 120 & 7.73 & 12.86 & 6.85 \\
\hline 14 & 300 & 1500 & 2 & 480 & 8.88 & 11.36 & 7.40 \\
\hline 15 & 300 & 1500 & 2 & 1440 & 9.94 & 11.53 & 8.86 \\
\hline
\end{tabular}

$5^{*}$ denotes the steel disc $(t=5 \mathrm{~mm})$ surface roughness was increased by adding mortar.

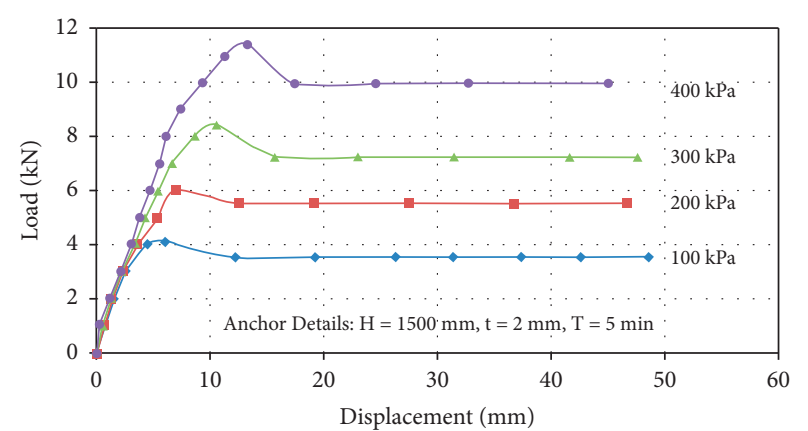

FIgURE 3: Uplift force of inflatable anchors versus displacement under various inflation pressures.

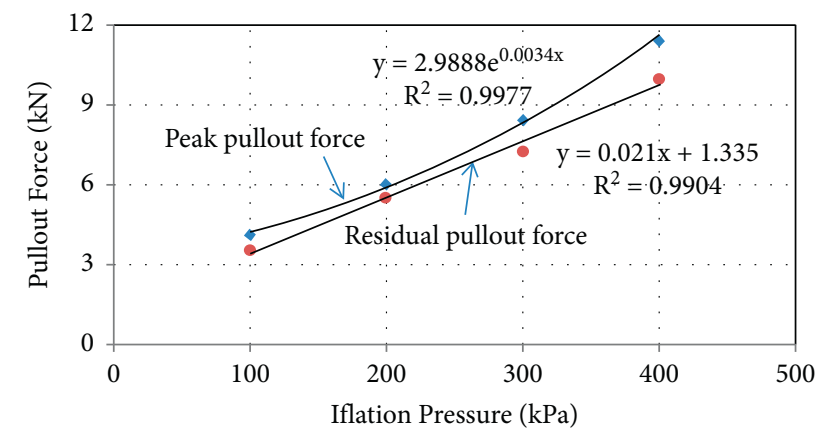

Figure 4: The relations between peak/residual uplift force and inflation pressures.

0.81 times and then increased to 2.52 times and 1.24 times of the previous inflation pressure, respectively, which is shown in Table 2. This result indicates that increasing inflation pressure leads to a greater difference between peak uplift force and residual uplift force.

3.2. Effect of Steel Disc Thickness (D). The lateral steel panel, which transmits the forces between the inflated pneumatic bag and the rock mass, has the most direct influence on "the uplift bearing capacity" of the proposed inflatable anchor. In order to investigate the effect of steel panel thickness on "the uplift bearing capacity," three steel panels with thicknesses of $1 \mathrm{~mm}, 2 \mathrm{~mm}$, and $5 \mathrm{~mm}$ were tested. Figures 5(a) and 5(b) show the association between "the uplift bearing capacity" and displacement when the inflation pressure is, respectively, $200 \mathrm{kPa}$ and $300 \mathrm{kPa}$. When the thickness of the steel panel increased from $1 \mathrm{~mm}$ to $2 \mathrm{~mm}$ and the inflation pressure reached $200 \mathrm{kPa}$, "the ultimate uplift bearing capacity" of the proposed inflatable anchor increased from $5.17 \mathrm{kN}$ to $6.01 \mathrm{kN}$ (an increase of $16.2 \%$ ), and the residual uplift capacity increased from $4.45 \mathrm{kN}$ to $5.55 \mathrm{kN}$ (an increase of $24.7 \%$ ). With a thickness of $5 \mathrm{~mm}$, the ultimate and residual uplift capacity increased to $6.52 \mathrm{kN}$ (an increase of $8.4 \%$ ) and $5.67 \mathrm{kN}$ (an increase of $2.1 \%$ ), respectively. Similarly, for the case of $300 \mathrm{kPa}$ inflation pressure, an increase of thickness caused the ultimate uplift capacity of the anchor to increase by $21.7 \%$ (from $1 \mathrm{~mm}$ to $2 \mathrm{~mm}$ ) and $2.6 \%$ (from $2 \mathrm{~mm}$ to $5 \mathrm{~mm}$ ) and the residual uplift capacity of the anchor to increase by $22.2 \%$ (from $1 \mathrm{~mm}$ to $2 \mathrm{~mm}$ ) and $1.8 \%$ (from $2 \mathrm{~mm}$ to $5 \mathrm{~mm}$ ). An observation of the physical state of the recovered steel panels showed that the trapezoidal panel (1 mm thickness) suffered from plastic deformation. However, the $2 \mathrm{~mm}$ - and $5 \mathrm{~mm}$-thick panels did not suffer any plastic deformation. Therefore, the results demonstrate that, after a certain point, increasing the thickness of the steel panels will not improve uplift capacity.

In an effort to explore the influence of the surface roughness of the steel panel on "the uplift bearing capacity" of the proposed inflatable anchor, the surface of a $5 \mathrm{~mm}$ thick steel panel was wrapped with an inner layer of carbon fiber cloth and coated with an outer layer of cement mortar to increase the surface roughness of the steel panel. Table 1 shows that, at $200 \mathrm{kPa}$ inflation pressure, an increase of surface roughness increased the ultimate uplift capacity from $6.52 \mathrm{kN}$ to $6.94 \mathrm{kN}$ (an increase of 6.4\%) and "the residual uplift bearing capacity" from $5.67 \mathrm{kN}$ to $5.85 \mathrm{kN}$ (an increase of $3.1 \%)$. At $300 \mathrm{kPa}$, the ultimate and residual 
TABLE 2: The difference value between peak pullout force and residual pullout force $\left(\Delta_{F}\right)$ under different inflation pressures.

\begin{tabular}{|c|c|c|c|c|}
\hline Test no. & Inflation pressure $P(\mathrm{kPa})$ & Peak uplift force $P_{\text {ult }}(\mathrm{kN})$ & Residual uplift force $R(\mathrm{kN})$ & $\Delta_{F}(\mathrm{kN})$ \\
\hline 1 & 100 & 4.12 & 3.55 & 0.57 \\
\hline 2 & 200 & 6.01 & 5.55 & 0.46 \\
\hline 3 & 300 & 8.42 & 7.26 & 1.16 \\
\hline 4 & 400 & 11.42 & 9.98 & 1.44 \\
\hline
\end{tabular}

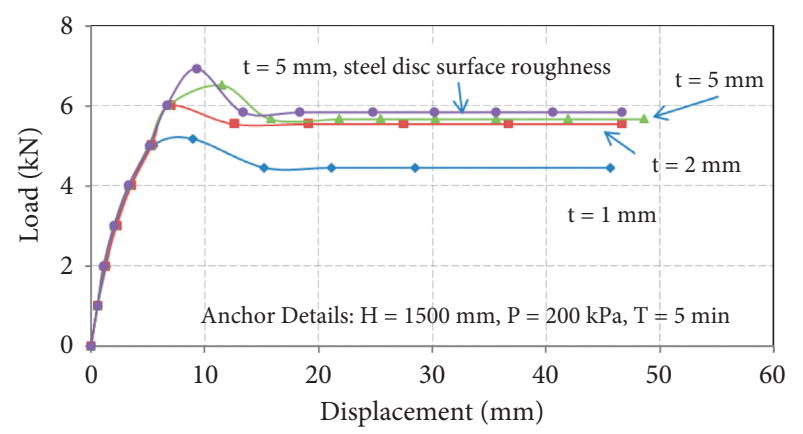

(a)

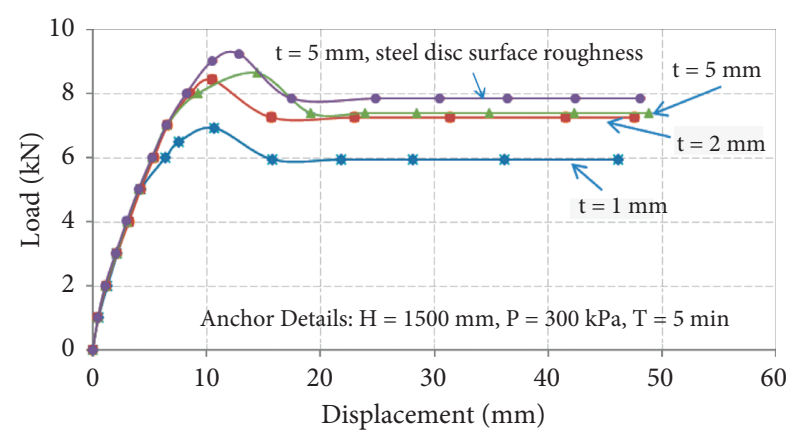

(b)

Figure 5: Uplift force of inflatable anchors versus displacement under various steel disc thicknesses. (a) Inflation pressure, $P=200 \mathrm{kPa}$. (b) Inflation pressure, $P=300 \mathrm{kPa}$.

"uplift bearing capacity" of the proposed inflatable anchor increased by $6.7 \%$ and $6.1 \%$, respectively. These results mean that "the uplift bearing capacity" of the proposed inflatable anchor cannot be effectively enhanced by simply increasing the surface roughness of the steel panel.

3.3. Effect of Embedment Depth (H). Figure 6 shows the association between the uplift bearing capacity of the proposed inflatable anchor corresponding to the displacement under embedment depths of $1.5 \mathrm{~m}, 2.0 \mathrm{~m}$, and $2.5 \mathrm{~m}$. The pressure is held constant at $300 \mathrm{kPa}$. The data show that "the uplift bearing capacity" increased with the embedment depth. When the embedment depth of the anchor is $1.5 \mathrm{~m}$, $2.0 \mathrm{~m}$, and $2.5 \mathrm{~m}$, the corresponding "ultimate uplift bearing capacity" of the proposed inflatable anchor is $8.42 \mathrm{kN}$, $9.29 \mathrm{kN}$, and $10.54 \mathrm{kN}$, with an increase of $10.3 \%$ and $13.4 \%$, respectively. "The residual uplift bearing capacity" also increases with the increase of depth, which is $7.26 \mathrm{kN}, 8.15 \mathrm{kN}$, and $9.06 \mathrm{kN}$, with an increase of $12.3 \%$ and $11.2 \%$, respectively. The relationship between "uplift bearing capacity" and embedment depth is analysed exactly in Figure 7. It can be found that the peak pullout force shows an exponential growth trend with the increase of embedment depth, and the residual pullout force increases linearly. The main reason can be explained as follows: with the increase of embedment depth, pressure of soil on the anchor correspondingly increases, so the lateral resistance between the soil and anchor increases.

Similar to the analysis of the effect of inflation pressure, the $K$ values of the anchor under different embedment depths are $0.80 \mathrm{kN} / \mathrm{mm}, 1.14 \mathrm{kN} / \mathrm{mm}$, and $1.16 \mathrm{kN} / \mathrm{mm}$, respectively. This means that the ability of the anchor to resist deformation gets stronger with the increase in

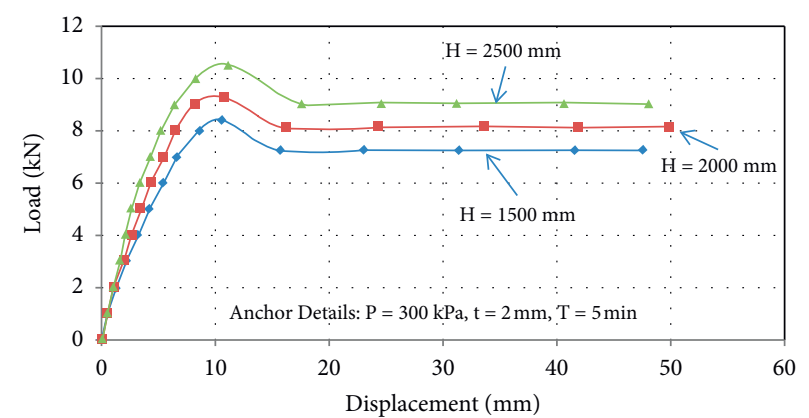

FIgURE 6: Anchor uplift force versus displacement for various embedment depths.

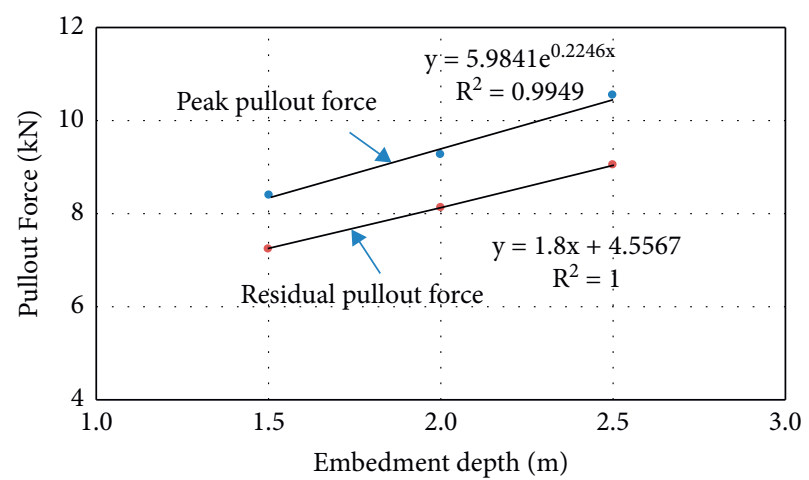

FIgURE 7: The relations between peak/residual uplift force and embedment depth.

embedment depth. It can be seen from Table 3 that the difference value between peak pullout force and residual pullout force, $\Delta_{F}$, first remains unchanged and then slightly increases (an increase of 20\%). 
TABLE 3: The difference value between peak pullout force and residual pullout force $\left(\Delta_{F}\right)$ under different embedment depths.

\begin{tabular}{|c|c|c|c|c|}
\hline Test no. & Embedment depth $H(\mathrm{~mm})$ & Peak uplift force $P_{\text {ult }}(\mathrm{kN})$ & Residual uplift force $R(\mathrm{kN})$ & $\Delta_{F}(\mathrm{kN})$ \\
\hline 3 & 1500 & 8.42 & 7.26 & 1.16 \\
\hline 11 & 2000 & 9.29 & 8.15 & 1.14 \\
\hline 12 & 2500 & 10.54 & 11.06 & 1.48 \\
\hline
\end{tabular}

No clear changes to the displacement corresponding to the residual uplift capacity are observed with the increase of embedment depth. The displacement is around $10.8 \mathrm{~mm}$ (as shown in Table 1). Compared with other tests, the following conclusion can be drawn: when the load increases to "the ultimate uplift bearing capacity," the corresponding displacement between the anchor and soil is closely connected with inflation pressure and is almost unaffected by embedment depth.

Figure 8 shows the association between "the uplift bearing capacity" factor $\left(N_{\gamma}\right)$ and the relative embedment depth $(H / D)$. In the above parameters, $N_{\gamma}=p \cdot$ ult $/(\gamma * H)$, where $p$.ult $=$ ultimate plate bearing pressure $\left(p_{\text {ult }} /\right.$ anchor plate area). When the relative embedment depth increased from 12.5 to 16.67 and then from 16.67 to 20.83 , the bearing capacity factor $\left(N_{\gamma}\right)$ decreased from 26.00 to 21.51 (a decrease of 20.87\%) and then from 21.51 to 19.53 (a decrease of $10.14 \%)$.

3.4. Time Lapse between Anchor Inflation and Uplift (T). When changing the stress conditions of soft clay, the pore water pressure in the soil body will gradually dissipate with time [9, 38-40]. In this study, the anchorage soil layer in the test is silt clay with a moisture content of $30.9 \%$. The soil is saturated, and when the pressure from the inflated anchor squeezes the surrounding hole wall, the excess pore water pressure of the surrounding soil around the anchorage cavity experiences transitions from a state of generation to a state of dissipation. Figure 8 shows the relationship between "the uplift bearing capacity" and the displacement at different times. Figure 9 shows that when the uplift test is conducted immediately after the inflation of the anchor, i.e., $T=5 \mathrm{~min}$, the ultimate uplift capacity is $8.42 \mathrm{kN}$ with a displacement of $10.36 \mathrm{~mm}$, and the residual uplift capacity is $8.42 \mathrm{kN}$. After 2 hours ( $T=120 \mathrm{~min}$ ), the ultimate uplift capacity is reduced to $7.73 \mathrm{kN}$ with a displacement of $12.86 \mathrm{~mm}$, and the residual uplift bearing capacity is reduced to $6.85 \mathrm{kN}$. After 8 hours $(T=480 \mathrm{~min})$, the ultimate uplift capacity increased to $8.88 \mathrm{kN}$ with a reduced displacement of $11.357 \mathrm{~mm}$, and the residual uplift capacity increased to $7.40 \mathrm{kN}$. After 24 hours $(T=1400 \mathrm{~min}$ ), the ultimate uplift capacity reached $7.73 \mathrm{kN}$ with a shift of $11.53 \mathrm{~mm}$, and "the residual uplift bearing capacity" reached $8.86 \mathrm{kN}$.

Therefore, the results indicate that "the uplift bearing capacity" of the anchor in the soft clay will first experience an initial decrease before gradually increasing due to the changing state of hole water pressure in the soil. When the airbag is inflated, pressure from the steel panels against the cavity walls presses excessive pore water from the soil of the cavity wall. Released pore water gradually seeps around the walls of the cavity and reduces the friction between the steel

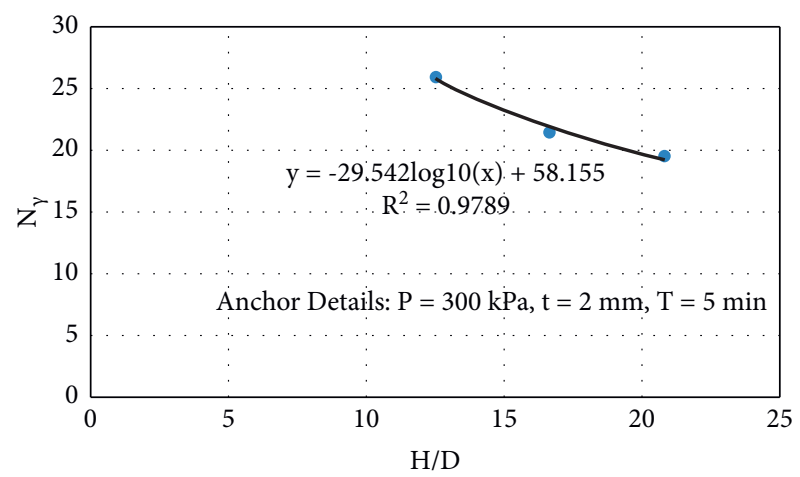

Figure 8: Bearing capacity factor $(N \gamma)$ versus the relative embedment depth $(H / D)$.

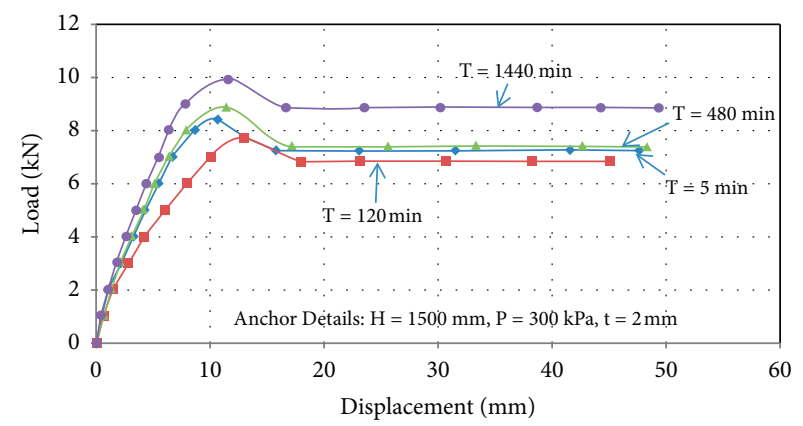

FIGURE 9: Uplift force of inflatable anchors versus displacement under various times elapsed between anchor inflation and uplift.

panels and soil mass, thereby reducing uplift capacity. However, the pore water pressure dissipates over time, and the effective stress of the soil mass increases again, which contributes to the increasing uplift capacity of the anchor as time progresses. In the experiment, by waiting 24 hours, "the uplift bearing capacity" of the proposed inflatable anchor increased by $18.1 \%$ with a minor increase of displacement, and the residual uplift capacity increased by $22 \%$.

\section{Advantages of the Inflatable Recyclable Anchor in the Tube Piece Type}

Comparing with the anchor bolt designed and studied by Newson et al. [7] and Cao et al. [12, 13], the major improvements of the new anchor proposed in this study include the following: (1) the diameter of the rubber pneumatic bag is increased from $35 \mathrm{~mm}$ to $100 \mathrm{~mm}$; (2) the pneumatic bag is additionally surrounded by steel panels. The experimental results demonstrate that the uplift capacity of the new anchor is enhanced compared to prior designs. The ultimate uplift capacity of the anchor proposed by 
Newson et al. [7] is $0.34 \mathrm{kN}$ with a displacement of about $75 \mathrm{~mm}$ under an inflation pressure of $150 \mathrm{kPa}$. However, the uplift capacity of the anchor proposed in this study is $4.12 \mathrm{kN}$ with a displacement of $6.02 \mathrm{~mm}$ under an inflation pressure of $100 \mathrm{kPa}$. This means that compared with the anchor bolt studied by Newson et al. [7], the uplift capacity is enhanced by about 12 times, and the corresponding displacement is reduced to about $8 \%$ of the previous value. Based on previous studies, it is found that "the uplift bearing capacity" of the inflatable anchor will not hold lasting growth with the increase of embedded depth, and the inflation pressure, which is instrumental in promoting "uplift bearing capacity" of the inflatable anchor, is low compared with experiments conducted by Newson et al. [7]. So, a conclusion can be drawn that "the uplift bearing capacity" of the inflatable recyclable anchor proposed in this study has been greatly enhanced; thus, the novel recyclable anchor has a better application prospect in practical engineering.

In order to further explore the potential applications of the proposed anchor in practical engineering, a comparative test of a traditional bonded anchor was conducted in the same site and soil conditions as those of the proposed anchor. Three grouted anchors of $18 \mathrm{~mm}$ diameter bars, whose length of the anchorage end is $1 \mathrm{~m}$, were used to carry out the comparative uplift test. The properties of the cavity are as follows: diameter is $120 \mathrm{~mm}$ and depth is $2 \mathrm{~m}$. Cement mortar with a water-cement ratio of $1: 0.5$ is selected as grouting material. The uplift tests were conducted after 28 days of curing. The relationship between the uplift capacities and displacements of three traditional bonded anchors is shown in Figure 10.

Figure 10 shows that the ultimate uplift capacities of the three traditional grouted anchors are $11.37 \mathrm{kN}, 11.86 \mathrm{kN}$, and $12.73 \mathrm{kN}$, with displacements of $19.26 \mathrm{~mm}, 16.29 \mathrm{~mm}$, and $19.83 \mathrm{~mm}$, respectively. The average value of the ultimate uplift capacities is $12.02 \mathrm{kN}$, which is close to the ultimate uplift capacity of the proposed inflatable recyclable anchor under an inflation pressure of $400 \mathrm{kPa}$.

It can be found from Figure 11 that the bearing capacity of both proposed inflatable recyclable anchor and grouted anchor decreased abruptly when the load reached the ultimate bearing capacity of the two types of anchor. Unlike the inflatable anchor, the curve of the grouted anchor decreases consistently and does not reach a steady stage. In addition, the descent rate of the grouting bolt curve is faster than that of the inflatable anchor curve.

Figure 11 indicates that the ultimate bearing capacity of the two types of anchor is numerically close, but the corresponding displacement of the grouted anchor is 1.5 times of that of the novel inflatable anchor. On the contrary, the bearing capacity of the grouted anchor decreases faster than the inflatable anchor and will decrease consistently, which is disadvantageous in engineering application. On the contrary, the novel inflatable anchor performs better even after crossing its ultimate stage. The inflatable anchor experienced a smaller reduction in uplift bearing capacity and maintained a relatively higher uplift bearing capacity than traditional grouted anchors in the residual stage. In summary, compared to traditional grouted anchors, the proposed

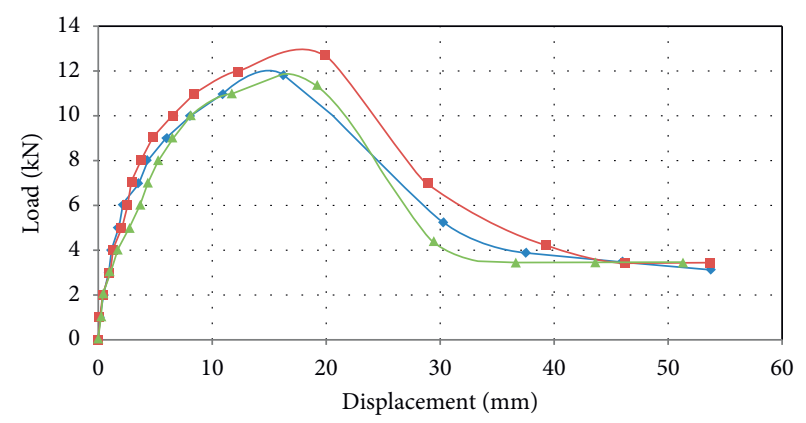

Figure 10: Uplift force of grouted anchors versus displacement.

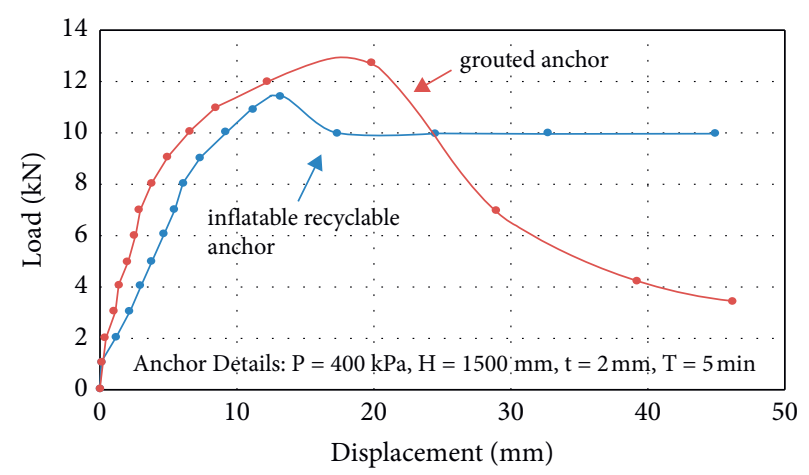

FIGURE 11: Uplift force of the inflatable recyclable anchor/grouted anchors versus displacement.

inflatable anchor has superior uplift bearing capacity and deformation resistances.

\section{Numerical Simulation Research}

5.1. Numerical Model. In order to further study the stressstrain distribution law of the surrounding soil under the pullout force of the inflatable anchor, a finite element numerical analysis was performed on the anchor pullout process using ABAQUS numerical simulation software. ABAQUS is one of the most powerful software used for finite element simulation in the world. It has a constitutive model that can reflect the characteristics of soil. It can solve relatively simple linear problems and complex nonlinear problems and has a powerful interface processing function to simulate the separation and slip between the soil and structure.

First, the anchor was subjected to an on-site pullout test in clay soil. The soil and anchor parameters are shown in Table 4. The parameters of the inflatable anchor are as follows: anchoring section $L=1200 \mathrm{~mm}$, diameter $D=120 \mathrm{~mm}$, and embedding depth $H=25 \mathrm{~mm}$. According to the structure of the anchor, the numerical model is simplified as follows: the inflation force of the airbag is equivalent to the pressure applied to the steel sheet (expansion anchoring force). The numerical simplified model is shown in Figure 12. Figure 13 shows the mechanical model of the inflatable retrievable anchor [34]. An axisymmetric model is used for numerical simulation. The soil is made of 
TABle 4: Material properties.

\begin{tabular}{lccccc}
\hline Material type & Elastic modulus $(\mathrm{MPa})$ & Poisson's ratio & Cohesion $(\mathrm{kPa})$ & ${\text { Internal friction angle }\left(^{\circ}\right)}^{\text {Density }\left(\mathrm{g} . \mathrm{cm}^{-3}\right)}$ \\
\hline Clay soil & 90 & 0.35 & 30.0 & 15 & 1.7 \\
Anchor & 206000 & 0.30 & - & - & 2.506 \\
\hline
\end{tabular}

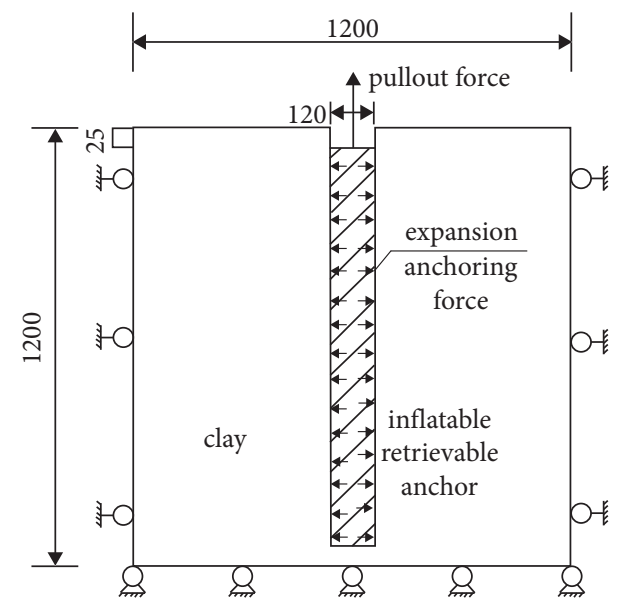

FIgURE 12: Model simplified diagram (unit: $\mathrm{mm}$ ).

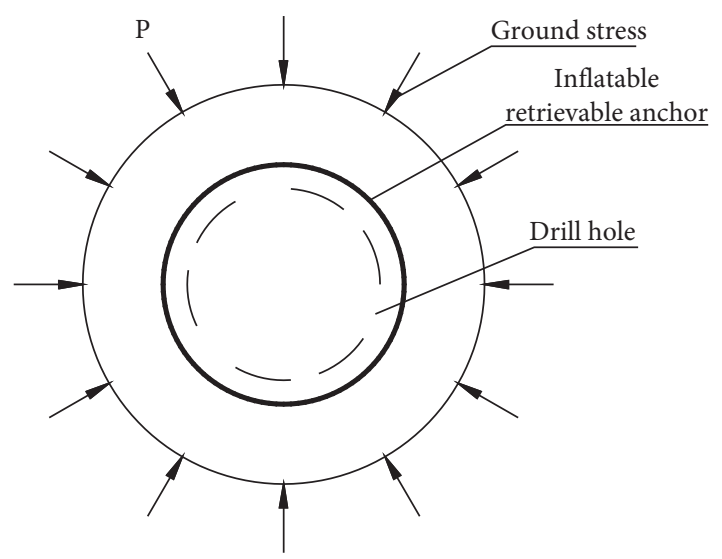

FIGURE 13: Mechanical diagram of the novel inflatable anchor [34].

elastoplastic material, and its yield surface obeys the Mohr-Coulomb criterion. And the anchor (steel sheet) is made of elastic material. The pulling force is loaded step by step and is stopped when it reaches $10 \mathrm{kN}$.

In the numerical simulation calculation results, the displacement of the proposed inflatable recyclable anchor is $4.32 \mathrm{~mm}$, and the displacement measured by the test is $4.00 \mathrm{~mm}$. The numerical model can better reflect the results of the pullout test. Therefore, exploratory research can be performed from the numerical simulation results.

5.2. Mechanical Model of the Contact Surface. Before studying the stress-strain distribution law of the surrounding soil under the pullout force of the inflatable recyclable anchor, it is necessary to figure out how the stress is transferred in the contact surface. When the anchor is in contact with the soil, the normal force and shear force are usually transmitted at the interface, so the normal and tangential effects between the contact surfaces should be considered.

The relationship between contact pressure and gap in the normal model of the contact surface is shown in Figure 14. The contact surfaces between the parts only transfer normal pressure $p$ when they are in contact with each other and are closed but do not transfer normal pressure when there is a gap between the contact surfaces; it is impossible for the hard-contact model to transfer tension on the contact surface stress.

For the tangential model of the contact surface, the isotropic friction model is used, as shown in Figure 15. Before the two contact surfaces start to move with each other, ABAQUS believes that when the contact surface is closed and bonded, the contact surface transmits shear forces (friction forces). In the tangential model, it is mainly based on whether the friction force between the contact surfaces exceeds the critical shear stress value $\tau_{\text {crit }}$ and then judges whether the contact surface has a relative sliding deformation. The calculation of $\tau_{\text {crit }}$ is based on Coulomb's law. The expression is $\tau_{\text {crit }}=\mu p$, where $\mu$ is the friction coefficient, the value depends on the shear rate, contact pressure, temperature, and other field variables and $p$ is the normal pressure between the contact surfaces.

5.3. Law of Soil Strain Distribution. With the increase of the pullout force, the strain distribution in the soil is shown in Figure 16.

In the numerical simulation, the analysis range of the surrounding soil is 10 times $(1200 \mathrm{~mm})$ the diameter of the anchor. After the anchor is inflated, the squeezed steel sheet contacts the soil. Due to the pullout force at the top, a frictional force is generated along the anchor at the contact surface. Anchor inflation can be equivalent to a round hole expansion process. Under contact compression, the strain distribution of the surrounding soil changes. It can be obtained from Figure 16 that the elastic strain distribution of the surrounding soil has different rules at different analysis steps. When the analysis step time is $0.20 \mathrm{~s}$, the tensile strain is concentrated within the depth of $200 \mathrm{~mm}$ near the top of the anchor. When the analysis step time is $0.50 \mathrm{~s}$, within the depth range, the tensile strain concentration area extends to the bottom of the anchor, and the tensile strain starts to increase; in the radial range, the distribution area of tensile strain tends to expand outward. When the analysis step time is $1.0 \mathrm{~s}$ and the pullout force is $10 \mathrm{kN}$, it can be seen that a tensile strain concentration zone along the depth range is formed in the surrounding soil. The position of the maximum strain distribution is developed from the vicinity of the top of the anchor to the bottom of the anchor.

During the pullout process of the anchor, the strain distribution of the surrounding soil has the following 


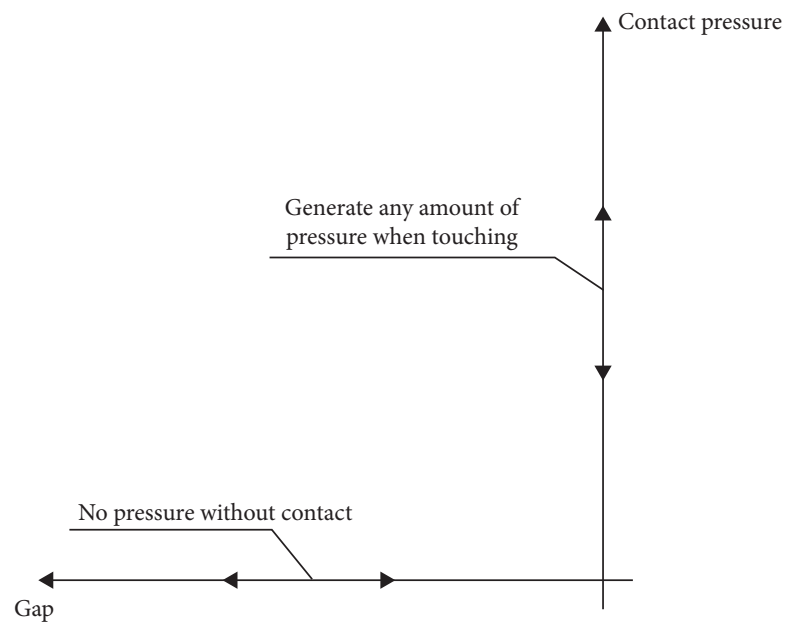

FigURE 14: Schematic diagram of hard contact.

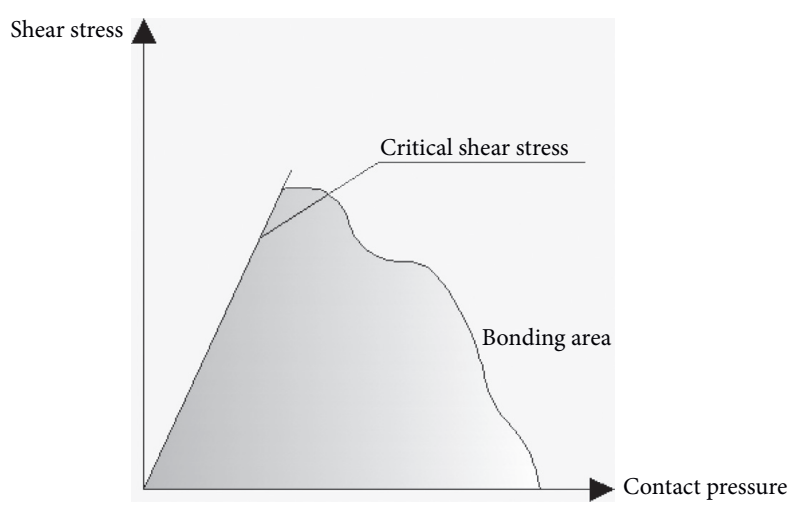

FIGURE 15: Schematic diagram of frictional contact.

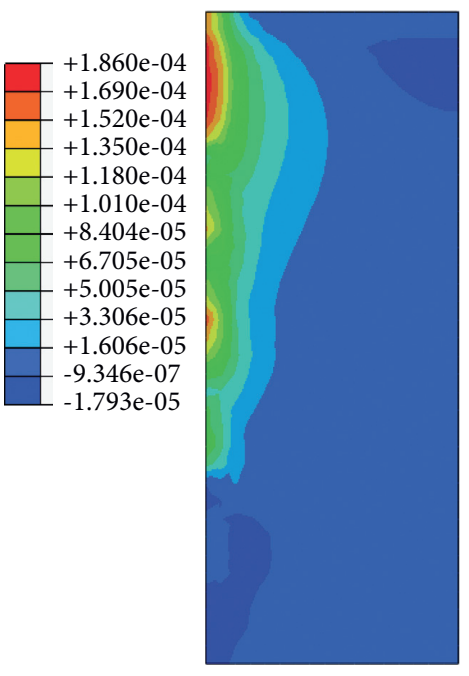

(a)

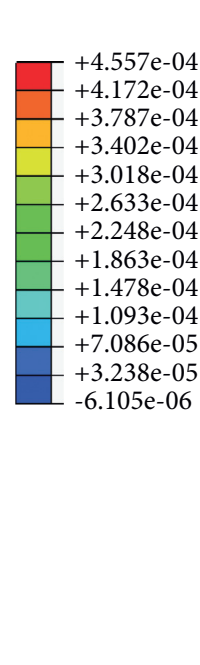

(b)

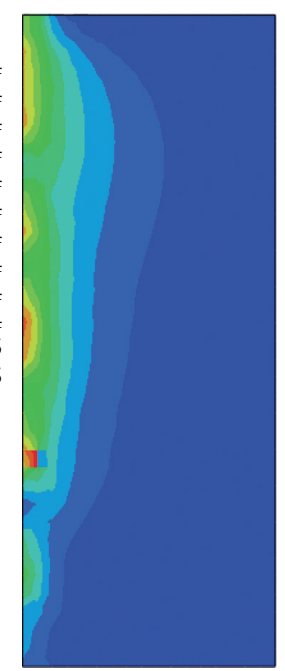

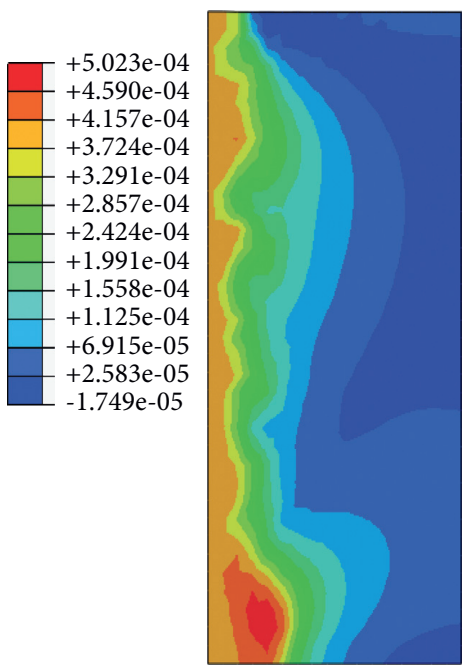

(c)

FIgURE 16: Contours of elastic strain in soil at different analysis steps. (a) $t=0.20 \mathrm{~s}$. (b) $t=0.50 \mathrm{~s}$. (c) $t=1.0 \mathrm{~s}$. 
changes: (1) the tensile strain concentration area develops from the top of the anchor to the bottom area and forms a through-type distribution area; (2) changes in the tensile strain area determine the ability of the soil to restrain the anchor. When the tensile strain area penetrates the depth range of the soil, the surrounding soil moves upwards as a whole, losing the restraining effect on the anchor.

\section{Conclusions}

In this study, the structure of a novel pattern of the inflatable anchor was designed and optimized. 15 field experiments were operated to investigate the uplift bearing performance of the proposed novel anchor, the distribution of the stress field in the surrounding soil was analysed, and conclusions were drawn as follows:

(1) The proposed inflatable anchor has good uplift and deformation responses in silty soil.

(2) "The uplift bearing performance" of the novel anchor not only depends on the inflation pressure, the thickness of the steel panels, and the embedment depth of the anchor rod but also relates to the waiting time for the uplift of the anchor after inflation and steel disc surface roughness.

(3) With the increase of inflation pressure, "the ultimate uplift bearing capacity," the corresponding displacement, and "the residual uplift bearing capacity" increase to different degrees, respectively. The inflation pressure and "the ultimate uplift bearing capacity" of the proposed anchor show an exponential relationship, and "the residual uplift bearing capacity" and inflation pressure have an evident linear correlation.

(4) Up to a certain point, the uplift capacity of the proposed anchor increases with the thickness of the steel panels and the embedment depth. After exceeding a certain value, the enhancement effect of the uplift capacity due to panel thickness and embedment depth is relatively small.

(5) The pore water pressure in the silty clay soil influences the uplift capacity of the inflatable anchor. As the pore water pressure transitions from a state of generation to a state of dissipation, the uplift capacity of the inflatable anchor initially undergoes a gradual increase before finally decreasing.

(6) During the pullout process of the inflatable anchor, there is a tensile stress concentration area in the surrounding soil with a radial distance of 2 to 3 times the diameter of the anchor. As the force increases, the tensile stress area moves towards bottom until a through area is formed.

The inflatable anchor is recyclable and reusable, can rapidly establish anchorage forces, and is thus suitable for a wide application potential. However, since research for inflatable anchors is still in its infancy, further experimental and theoretical studies need to be carried out, such as the effect of the rubber pneumatic bag's size and optimal shape of the steel panel on the uplift performance of the inflatable anchor, the theoretical support for the computation of the uplift capacity, and feasibility studies on the application of the inflation anchor in temporary anchorage engineering.

\section{Data Availability}

The data supporting the results of this study are available from the corresponding author upon request.

\section{Conflicts of Interest}

The authors declare that there are no conflicts of interest in this paper.

\section{Acknowledgments}

The research conducted in this paper was partially supported by the National Natural Science Foundation of China (Grant no. 51678066), Study on Failure Mechanism and Grouting Reinforcement Technology of Pipe Jacking Excavation in Overlying Water-Rich Sand Layer, Hubei Province (Grant no. 2020AC15), and Open Research Fund of the State Key Laboratory of Geomechanics and Geotechnical Engineering, Institute of Rock and Soil Mechanics, Chinese Academy of Sciences (Grant no. Z020013). The authors would also like to acknowledge the contributions of Civil Engineering at Yangtze University.

\section{References}

[1] M. Vogler, "The influence of urban boundary conditions on the design of deep excavations and foundation systems for high rising buildings using the example of Palais Quartier in Frankfurt am Main, Germany," Bauingenieur, vol. 85, pp. 273-281, 2010.

[2] V. Alireza, Y. Nordin, M. N. Norhazilan, A. Jurgita, and T. Jolanta, "Hybrid SWARA-COPRAS method for risk assessment in deep foundation excavation project: an Iranian case study," Journal of Civil Engineering and Management, vol. 23, pp. 524-532, 2017.

[3] M. Devon, D. Rasin, G. Alp, and O. Bora, "Support of 25m deep excavation using ground anchors in Russia," Proceedings-Institution of Civil Engineers, vol. 18, pp. 281-295, 2015.

[4] G. Christophe, J. C. Mark, and D. O. Conleth, "Recent advances in anchor design for floating structures," International Journal of Offshore and Polar Engineering, vol. 27, pp. 44-53, 2017.

[5] E. T. Brown, "Rock engineering design of post-tensioned anchors for dams-a review," Journal of rock mechanics and geotechnical engineering, vol. 7, no. 1, pp. 1-13, 2015.

[6] T. A. Newson, P. Bruning, and S. Gallagher, "An experimental study of inflatable offshore anchors," in Proceedings of the ISOPE 2003 Conference, pp. 127-135, Honolulu, HI, USA, May 2003.

[7] T. A. Newson, F. W. Smith, and P. Bruning, "An experimental study of inflatable offshore anchors in soft clay," in Proceedings of the ICOF 2003. BGA Conference on Foundations, pp. 695-704, Dundee, UK, September 2003.

[8] T. A. Newson, S. Hinchberger, and Y. Liang, "A numerical study of an inflatable anchor system," in Proceedings of the 60th Canadian Geotechnical Conference and 8th Joint CGS/ 
IAH-CNC Groundwater Conference, pp. 1258-1265, Ottawa, Canada, October 2007.

[9] Y. Liang, T. Newson, S. Hinchberger, and P. Larkin, "Numerical study of the mechanics of inflatable anchors in clay," in Proceedings of the ISOPE 2008 Conference, pp. 546-551, Vancouver, Canada, July 2008.

[10] Y. Liang, S. D. Hinchberger, and T. A. Newson, "Non-linear analysis of uplift tests on inflatable anchors in sand," in Proceedings of the Canadian Geotechnical Conference, pp. 1-8, Halifax, Canada, February 2009.

[11] T. Newson, S. Hinchberger, and Y. I. Liang, "The mechanics of inflatable anchors in cohesionless soil," Soils and Foundations, vol. 49, no. 3, pp. 409-420, 2009.

[12] J. W. Cao, W. X. Peng, Z. B. Peng, Z. M. He, and Q. Yin, "Experimental study on deformation and bearing features of inflatable anchors in sands," Journal of Central South University, vol. 42, pp. 1369-1374, 2011.

[13] J. W. Cao, Z. B. Peng, W. X. Peng, Z. M. He, and Q. Yin, "Model test study of inflated anchors in sands," Rock and soils mechanics, vol. 32, pp. 1957-1962, 2011.

[14] J. Zhang, Y. Li, Y. Huang, J. Jiang, and S.-C. Ho, “A feasibility study on timber moisture monitoring using piezoceramic transducer-enabled active sensing," Sensors, vol. 18, no. 9, 3100 pages, 2018.

[15] J. Zhang, Y. Huang, and Y. Zheng, "A feasibility study on timber damage detection using piezoceramic-transducer-enabled active sensing," Sensors, vol. 18, no. 5, 1563 pages, 2018.

[16] G. Du, J. Zhang, J. Zhang, and G. Song, "Experimental study on stress monitoring of sand-filled steel tube during impact using piezoceramic smart aggregates," Sensors, vol. 17, no. 8, 1930 pages, 2017.

[17] J. Zhang, Y. Li, Y. Zheng, and Z. Wang, "Seismic damage investigation of spatial frames with steel beams connected to L-shaped concrete-filled steel tubular (CFST) columns," Applied Sciences, vol. 8, no. 10, 1713 pages, 2018.

[18] J. C. Zhang, C. Zhang, J. H. Xiao, and J. W. Jiang, "PZT-based electromechanical impedance method in monitoring the soil freeze-thaw process," Sensors, vol. 19, no. 5, 1107 pages, 2019.

[19] G. Wu, W. Chen, and H. Tian, "Numerical evaluation of a yielding tunnel lining support system used in limiting large deformation in squeezing rock," Environ Earth Science, vol. 77, 439 pages, 2018.

[20] J. Shu, L. Jiang, P. Kong, P. Wang, and P. Zhang, "Numerical modeling approach on mining-induced strata structural behavior by considering the fracture-weakening effect on rock mass," Applied Sciences, vol. 9, 1832 pages, 2019.

[21] Q. Tan, X. Zou, Y. Ding, X. Zhao, and S. Qian, "The influence of dynamic tissue properties on HIFU hyperthermia: a numerical simulation study," Applied Sciences, vol. 8, 1933 pages, 2018.

[22] T. L. Xiao, H. X. Qiu, and J. L. Li, "Seismic behaviors of concrete beams reinforced with steel-FRP composite bars under quasi-static loading," Applied Sciences, vol. 8, 1913 pages, 2018.

[23] X. Liu, S. Yang, Y. Liu, Y. Chi, and X. Gu, "Surface crack identification on a cylinder using the signal enhancement of the scanning laser line source method," Applied Sciences, vol. 8, 1796 pages, 2018.

[24] Z. Chen, H. Wang, H. Wang, H. Jiang, X. Zhu, and K. Wang, "Application of the hybrid simulation method for the fullscale precast reinforced concrete shear wall structure," $A p$ plied Sciences, vol. 8, 252 pages, 2018.

[25] T. L. Xiao, M. Huang, C. Cheng, and Y. L. He, "Experimental investigation on the mechanical characteristics and deformation behaviour of fractured rock-like material with one single fissure under the conventional triaxial compression," Shock and Vibration, vol. 2018, Article ID 2608639, 11 pages, 2018.

[26] G. F. Du, B. Milos, F. H. Wu et al., "Experimental and numerical studies on concrete filled circular steel tubular (CFCST) members under impact loads," International Journal of Civil Engineering, vol. 17, no. 3, 2018.

[27] J. C. Zhang, Y. S. Huang, Y. Chen, G. F. Du, and L. J. Zhou, "Numerical and experimental study on seismic behavior of concrete-filled T-section steel tubular columns and steel beam planer frames," Journal of Central South University, vol. 25, pp. 1774-1785, 2018.

[28] J. Li, Y. Wang, Z. Lu, and J. Li, "Experimental study and numerical simulation of a laminated reinforced concrete shear wall with a vertical seam," Applied Sciences, vol. 7, 629 pages, 2017.

[29] V. Sharma, F. Zivic, N. Grujovic, N. Babcsan, and J. Babcsan, "Numerical modeling and experimental behavior of closedcell aluminum foam fabricated by the gas blowing method under compressive loading," Materials, vol. 12, 1582 pages, 2019.

[30] J. Kaczmarczyk and A. Grajcar, "Numerical simulation and experimental investigation of cold-rolled steel cutting," $M a$ terials, vol. 11, 1263 pages, 2018.

[31] Á. Navarrete, F. Cook, D. Celentano, M. Cruchaga, and C. García-Herrera, "Numerical simulation and experimental validation of sheet laser forming processes using general scanning paths," Materials, vol. 11, 1262 pages, 2018.

[32] C. Yuan, L. Fan, J. F. Cui, and W. J. Wang, "Numerical simulation of the supporting effect of anchor rods on layered and nonlayered roof rocks," Advances in Civil Engineering, vol. 2020, Article ID 4841658, 14 pages, 2020.

[33] S. R. Kim, G. B. Shin, and C-K Chung, "Evaluation of optimum spacing between anchor bodies of distributive compression anchor using numerical simulation," Journal of the korean geotechnical society, vol. 35, pp. 29-39, 2019.

[34] T. L. Xiao and Y. L. He, "Experimental study of an inflatable recyclable anchor," Advances in Materials Science and Engineering, vol. 2018, Article ID 6940531, 10 pages, 2018.

[35] Specification of soil test, SL237-1999. The Industry Standard of People's Republic of China, China Water and Power Press, Beijing, China, 1999.

[36] C. Cao, T. Ren, and C. Chris, "Calculation of the effect of Poisson's ratio in laboratory push and pull testing of resinencapsulated bolts," International Journal of Rock Mechanics and Mining Sciences, vol. 64, pp. 175-180, 2013.

[37] Q. L. Chang, H. Q. Zhou, Z. H. Xie, and S.-P. Shen, “Anchoring mechanism and application of hydraulic expansion bolts used in soft rock roadway floor heave control," International journal of mining science and technology, vol. 23, pp. 323-328, 2013.

[38] K. D. Eigenbrod and J. P. Burak, "Field measurement of anchor forces, ground temperatures, and pore-water pressures behind a retaining structure in northwestern Ontario," Canadian Geotechnical Journal, vol. 29, pp. 112-116, 1992.

[39] J. C. Small, C. P. Thorne, and L. D. Ta, "Effect of pore pressure dissipation on the behavior of anchors in clay," in Proceedings of the ISOPE 1998 Conference, pp. 497-504, Montreal, Canada, May 1998.

[40] K. M. Shen, L. Z. Wang, Z. Guo, and D. S. Jeng, "Numerical investigations on pore-pressure response of suction anchors under cyclic tensile loadings," Engineering Geology, vol. 227, no. S1, pp. 108-120, 2017. 